\title{
Transarterial embolization for hepatocellular adenomas: a literature review
}

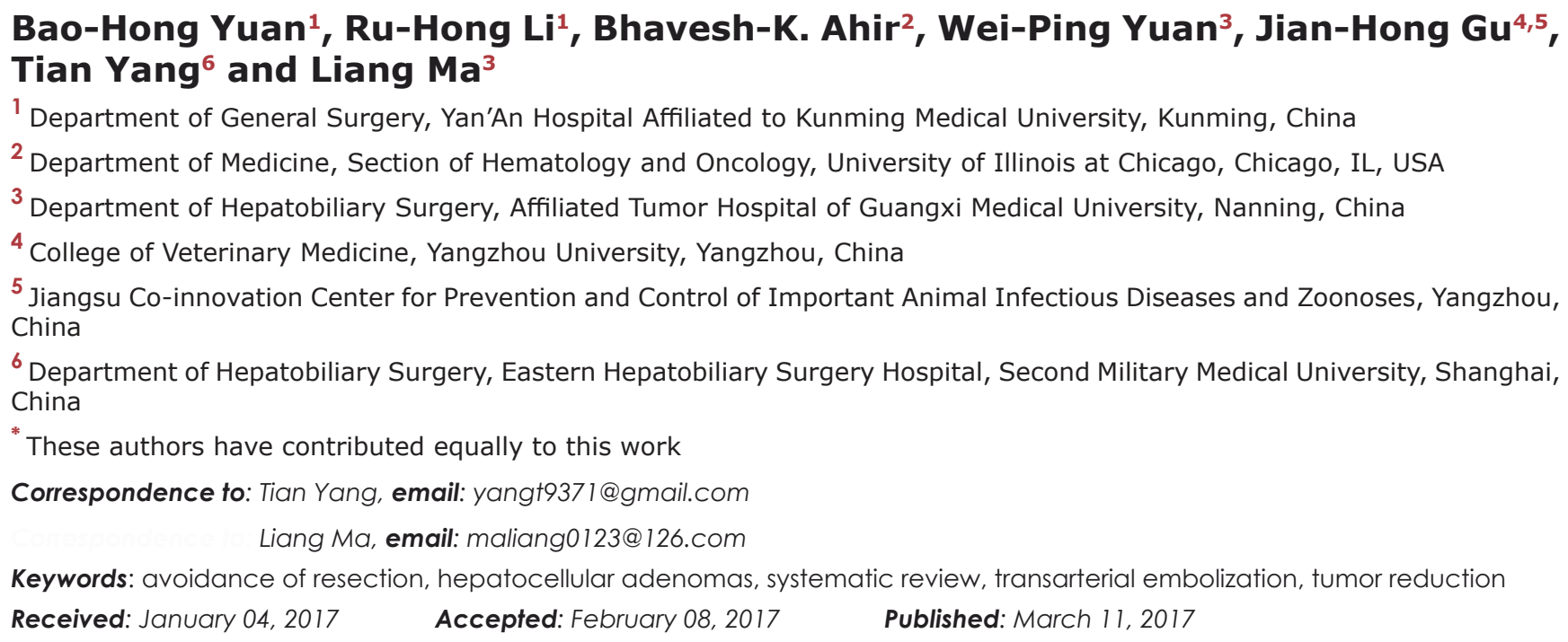

ABSTRACT

Since the utilization of transarterial embolization (TAE) for hepatocellular carcinoma, TAE is used to treat bleeding hepatocellular adenomas (HCAs) and occasionally, in symptomatic HCAs with large tumors. However, the role of TAE in an elective setting is uncertain. The present review aims to evaluate the benefits and harms of TAE in bleeding and non-bleeding HCAs, especially in an elective setting. A systematic review of studies published from January 2000 to December 2016 in the EMBASE, PubMed and Scopus databases was performed. Avoidance of resection and tumor reduction after TAE were the primary outcomes measure in both bleeding and non-bleeding HCAs. Twenty-one case series involving 1481 patients with HCAs were included in the analysis. Most of them were underwent hepatic resection. Only 148 (10\%) patients (involving 189 lesions) received TAE, including 93 (62.8\%) patients with bleeding HCAs and 55 (37.2\%) patients with non-bleeding HCAs. Based on data of 107 tumors, the rates of Complete Response and Partial Response were 10.3\% and $73.8 \%$, respectively. Hepatic resection was avoided in 72 of 148 (48.6\%) TAE treated patients. Intended elective TAE was performed in 45/148 (30.4\%) patients; $\mathbf{9 5 . 6} \%$ of them did not require further hepatic resection. No mortality or adverse side effects were reported during the hospitalization period. Therefore, Either in an elective setting or in the setting of bleeding, TAE can be considered safe in the management of HCAs. In the elective setting, TAE can be regarded as a reasonable alternative management to hepatic resection. High-quality prospective study with long-term follow-up is warranted.

\section{INTRODUCTION}

Hepatocellular adenomas (HCAs) is a very rare disease with malignant potential in Asian, but is highly prevalent in Europe [1]. The annual incidence of HCA is estimated to be $1 / 10^{6}$ among all population and 3 to 4 per
100,000 women with long-term use of oral contraceptives $[2,3]$. Symptomatic bleeding may be occurred in more than $14 \%$ patients with HCAs, and this risk will be higher with increasing tumor diameter [4]. The risk of malignant transformation, that is hepatocellular carcinoma (HCC), is about 4 to $6 \%$ in women and up to $47 \%$ in 
men in a long-term follow-up [4-7]. HCA is a benign tumor composed of hepatocytes. However, its exact pathophysiological mechanism remains unknown. The use of oral contraceptives is regarded as the main risk factor for HCAs among women. New risk factors for HCAs have emerged in recent years, including obesity, metabolic syndrome, and anabolic steroids exposure.

HCAs are usually discovered either incidentally on liver function test abnormalities or abdominal imaging performed for unrelated reasons. Therefore, most patients with HCAs have large tumors $(>5 \mathrm{~cm})$ at their first diagnosis. Due to the high risk of hemorrhage and potential malignant transformation, hepatic resection is considered as a treatment for HCAs. However, emergent hepatic resection for ruptured HCAs is associated with a mortality rate of 5 to $10 \%$ [8]. Elective transarterial embolization (TAE) prior to surgery is another choice of treatment because delayed hepatic resection may be associated with less blood loss and lower postoperative complications [8]. As HCA is hypervascular arterial lesion, TAE is also recommended for HCAs complicated by hemorrhage [8]. In addition, TAE may lead to size reduction in large and/or multiple HCAs or those unfavorably localized for hepatic resection, and then theoretically reduce the risk of malignant transformation [9].
Though some case series studies and case reports from single-center experiences in the clinical management of HCAs were reported, these studies included only a limited number of patients. On the other hand, the role of TAE used in an elective setting where no acute intervention is needed is unknown. The aim of the present systematic review is to describe presentation, surgery avoided, tumor size reduction and incidence of malignant transformation in patients undergoing TAE for HCAs.

\section{RESULTS}

\section{Results of literature search}

A total of 231 studies were identified using our search criteria for screening (Figure 1). Following assessment by exclusion criteria adopted, 26 were rejected and 180 studies remained for abstract review. Following abstract review, 137 studies were excluded and 43 studies remained for full-text eligibility assessment. Twenty-one studies meeting the inclusion criteria were identified after thorough assessment of the full manuscripts [10-30]. Of these, two studies by Dokmak [18, 19] and other two
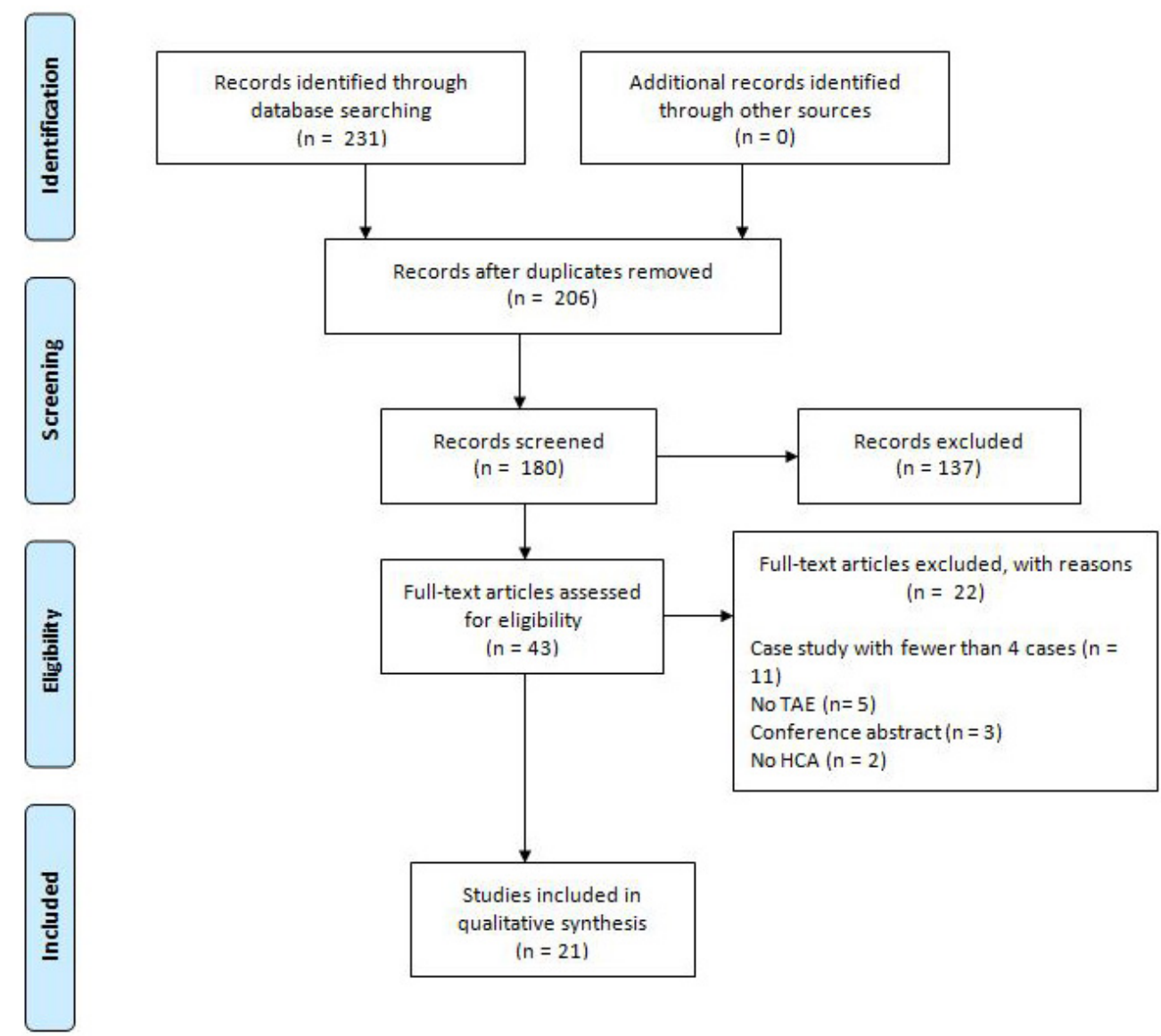

Figure 1: PRISMA flow diagram. 
Attached Table: Quality appraisal checklist for case series studies based on the Institute of Health Economics criteria [39]

\begin{tabular}{|c|c|c|c|c|c|c|c|c|c|c|c|c|c|c|c|c|c|c|c|c|c|}
\hline \multirow{2}{*}{ Author (year) } & \multirow{2}{*}{\begin{tabular}{|l}
$\begin{array}{l}\text { Study } \\
\text { objective }\end{array}$ \\
1
\end{tabular}} & \multicolumn{3}{|c|}{ Study design } & \multicolumn{3}{|c|}{ Study population } & \multicolumn{2}{|c|}{\begin{tabular}{|l} 
Intervention \\
and \\
intervention
\end{tabular}} & \multicolumn{4}{|c|}{ Outcome measure } & \multirow{2}{*}{$\begin{array}{l}\begin{array}{l}\text { Statistical } \\
\text { analysis }\end{array} \\
14\end{array}$} & \multicolumn{5}{|c|}{ Results and conclusions } & \multirow{2}{*}{ 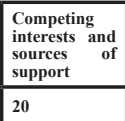 } & \multirow{2}{*}{\begin{tabular}{|l} 
Total \\
score
\end{tabular}} \\
\hline & & 2 & $3^{*}$ & 4 & 5 & 6 & 7 & 8 & 9 & 10 & $11 \dagger$ & 12 & 13 & & $15 *$ & 16 & 17 & 18 & 19 & & \\
\hline Abu Hilal 2011 & Yes & Yes & No & Yes & Yes & Yes & Yes & Yes & Yes & Yes & Unclear & Yes & Yes & Yes & Unclear & Unclear & Partial & Yes & Yes & No & 14 \\
\hline Battula 2012 & Yes & No & No & Yes & Yes & Yes & Yes & Yes & Yes & Yes & Unclear & Yes & Yes & Unclear & Yes & Yes & Partial & Yes & Yes & Yes & 15 \\
\hline Bieze 2014 & Yes & Yes & No & Yes & Yes & Yes & Yes & Yes & Yes & Yes & Unclear & Yes & Yes & Yes & No & Yes & Yes & Yes & Yes & Yes & 17 \\
\hline $\begin{array}{l}\text { Bunchorntavakul } \\
2011\end{array}$ & Yes & No & No & Yes & Yes & Yes & Yes & Yes & Yes & Yes & Unclear & Yes & Yes & Yes & No & Yes & Yes & Yes & Yes & Yes & 16 \\
\hline Cho 2008 & Yes & No & No & Yes & Yes & Yes & Yes & Yes & Yes & Yes & Unclear & Yes & Yes & Yes & No & Yes & Partial & Yes & Yes & Yes & 15 \\
\hline de'Angelis 2014 & Yes & No & No & Yes & Yes & Yes & Yes & Yes & Yes & Yes & Unclear & Yes & Yes & Yes & No & Yes & Yes & Yes & Yes & Yes & 16 \\
\hline Deneve 2009 & Yes & No & Yes & Yes & Yes & Yes & Yes & Yes & Yes & Yes & Unclear & Yes & Yes & Yes & Yes & Yes & Yes & Yes & Yes & Yes & 18 \\
\hline Deodhar 2011 & Yes & No & No & Yes & Yes & Yes & Yes & Yes & Yes & Yes & Unclear & Yes & Yes & Unclear & No & Yes & No & Yes & Yes & Yes & 14 \\
\hline Dokmak 2009 & Yes & No & No & Yes & Yes & Yes & Yes & Yes & Yes & Yes & Unclear & Yes & Yes & Yes & Yes & Yes & Yes & Yes & Yes & Yes & 17 \\
\hline Dokmak 2015 & Yes & Yes & No & Yes & Yes & Yes & Yes & Yes & Yes & Partial & Unclear & Yes & Yes & Unclear & Yes & Yes & Partial & Yes & Yes & Yes & 15 \\
\hline Erdogan 2006 & Yes & No & No & Yes & Yes & Yes & Yes & Yes & Yes & Yes & Unclear & Yes & Yes & Yes & No & Yes & Yes & Yes & Yes & No & 15 \\
\hline Erdogan 2007 & Yes & Yes & No & Yes & Yes & Yes & Yes & Yes & Yes & Partial & Unclear & Yes & Yes & Unclear & No & Yes & No & Yes & Yes & No & 13 \\
\hline Karkar 2013 & Yes & No & No & Yes & Yes & Yes & Yes & Yes & Yes & Yes & Unclear & Yes & Yes & Yes & Yes & Yes & Yes & Yes & Yes & Yes & 17 \\
\hline Kim 2007 & Yes & No & No & Yes & Yes & Yes & Yes & Yes & Yes & Yes & Unclear & Yes & Yes & Yes & Yes & Yes & Partial & Yes & Yes & Yes & 16 \\
\hline Laurent 2016 & Yes & No & Yes & Yes & Yes & Yes & Yes & Yes & Yes & Partial & Unclear & Yes & Yes & Yes & Yes & Yes & Yes & No & Yes & Yes & 16 \\
\hline Marini 2002 & Yes & Yes & No & Yes & Yes & Yes & Yes & Yes & Yes & Partial & Unclear & \begin{tabular}{|l} 
Partial \\
\end{tabular} & Yes & Unclear & No & Yes & No & Yes & Yes & No & 12 \\
\hline Ramia 2014 & Yes & No & Yes & Yes & Yes & Yes & Yes & Yes & Yes & Partial & Unclear & Yes & Yes & Unclear & Yes & Yes & Yes & Yes & Yes & Yes & 16 \\
\hline Srirattanapong 2014 & Yes & No & No & Yes & Yes & Yes & Yes & Yes & Yes & Yes & Unclear & Yes & Yes & Unclear & Yes & Yes & Yes & Yes & Yes & No & 15 \\
\hline Stoot 2007 & Yes & Yes & No & Yes & Yes & Yes & Yes & Yes & Yes & Yes & Unclear & Yes & Yes & Yes & No & Yes & Partial & Yes & Yes & No & 15 \\
\hline Toso 2005 & Yes & No & No & Yes & Yes & Yes & Yes & Yes & Yes & Partial & Unclear & Yes & Yes & Unclear & Yes & Yes & No & Yes & Yes & No & 13 \\
\hline van der Windt 2006 & Yes & Yes & No & Yes & Yes & Yes & Yes & Yes & Yes & Yes & Unclear & Yes & Yes & Yes & No & Yes & Yes & Yes & Yes & No & 16 \\
\hline
\end{tabular}

* Item 3: most of the studies were based on single center.

$\dagger$ Item 11: we do not know if the outcome assessors were blinded to the intervention that patients receive.

+ Item 15: follow-up of at least 36 months was considered appropriate to judge the change of tumor diameter and new lesions developed.

$\S$ All the total score were more than $14(86 \%)$. These studies were deemed sufficient.

Table 1: Characteristics of the included studies

\begin{tabular}{|c|c|c|c|c|c|c|c|c|c|c|}
\hline \multirow[b]{2}{*}{ Studies } & \multirow[b]{2}{*}{ Country } & \multirow[b]{2}{*}{$\begin{array}{l}\text { Included } \\
\text { period }\end{array}$} & \multirow[b]{2}{*}{$\begin{array}{l}\text { No. of } \\
\text { total }\end{array}$} & \multicolumn{7}{|c|}{ Characteristics of patients with transarterial embolization } \\
\hline & & & & $\begin{array}{l}\begin{array}{l}\text { No. of of } \\
\text { elective } \\
\text { patients }\end{array} \\
\end{array}$ & $\mathbf{M} / \mathbf{F}$ & $\begin{array}{l}\text { Mean } \\
\text { yr* }^{*}\end{array}$ & $\begin{array}{l}\text { Patients } \\
\text { embolized } \\
\text { (bleeding/non- } \\
\text { bleeding) }\end{array}$ & $\begin{array}{l}\text { Tumors embolized } \\
\text { (bleeding/non- } \\
\text { bleeding) }\end{array}$ & Adenomatosis & $\begin{array}{l}\text { Median } \\
\text { follow-up } \\
\text { (months) }\end{array}$ \\
\hline Abu Hilal $2011[10]$ & UK & $2005-2009$ & 13 & 0 & $0 / 3$ & 27 & $3 / 0$ & $5 / 0$ & 2 & - \\
\hline Battula 2012 [11] & UK & 1995-2011 & 27 & 0 & - & - & $2 / 0$ & $2 / 0$ & 0 & 57 \\
\hline Bieze 2014 [12] & Netherlands & $2008-2012$ & 45 & 0 & $1 / 44^{*}$ & 39 & $7 / 2$ & $7 / 3$ & 0 & 14 \\
\hline Bunchorntavakul 2011 [13] & USA & $2005-2010$ & 60 & 7 & $4 / 56^{*}$ & 36 & $4 / 13$ & $4 / 13$ & 0 & 31 \\
\hline Cho 2008 [14] & USA & 1988-2007 & 41 & 0 & $3 / 38^{*}$ & 38 & $1 / 0$ & $1 / 0$ & 0 & 23 \\
\hline de'Angelis 2014 [15] & France & 1989-2012 & 62 & 0 & $3 / 59^{*}$ & 36 & $6 / 0$ & $6 / 0$ & 0 & 12 \\
\hline \begin{tabular}{|l|} 
Deneve 2009 [16] \\
\end{tabular} & USA & 1997-2006 & 124 & 5 & $8 / 116^{*}$ & 39 & $6 / 5$ & $6 / 5$ & 0 & 36 \\
\hline Deodhar 2011 [17] & USA & 2006-2007 & 8 & 7 & $1 / 7$ & 36 & $1 / 7$ & $2 / 15$ & 0 & 24 \\
\hline Dokmak 2009 [19] & France & 1990-2004 & 122 & 0 & $14 / 108^{*}$ & 37 & $12 / 0$ & $12 / 0$ & 0 & 70 \\
\hline Dokmak 2015 [18] & France & 2004-2013 & 116 & 0 & 19/97 & 42 & $2 / 0$ & $2 / 0$ & 0 & 38 \\
\hline Erdogan 2006 [20] & Netherlands & 1990-2005 & 22 & 0 & $0 / 22$ & 36 & $1 / 1$ & $1 / 1$ & 0 & 25 \\
\hline Erdogan 2007 [21] & Netherlands & - & 6 & 0 & $1 / 5$ & 40 & $6 / 0$ & $6 / 0$ & 0 & 24 \\
\hline Karkar 2013 [22] & USA & 1992-2011 & 52 & 19 & $7 / 45^{*}$ & 39 & $5 / 20$ & $5 / 33$ & 7 & 56 \\
\hline Kim 2007 [23] & Korea & 1989-2006 & 7 & 6 & $5 / 2$ & 25 & $1 / 6$ & $3 / 6$ & 0 & 88 \\
\hline \begin{tabular}{|l|} 
Laurent 2016 [24] \\
\end{tabular} & Europe† & 1986-2013 & 573 & 0 & $62 / 511^{*}$ & 37 & $15 / 0$ & $15 / 0$ & 0 & 91 \\
\hline Marini 2002 [25] & France & $1995-2000$ & 20 & 0 & $0 / 3$ & 35 & $3 / 0$ & $3 / 0$ & 0 & 6 \\
\hline Ramia 2014 [26] & Spain & 1995-2011 & 81 & 0 & $20 / 61^{*}$ & 40 & $1 / 0$ & $1 / 0$ & 0 & 43 \\
\hline Srirattanapong 2014 [27] & USA & $2002-2012$ & 18 & 1 & $1 / 1$ & 24 & $1 / 1$ & $1 / 1$ & 0 & 41 \\
\hline Stoot 2007 [28] & \begin{tabular}{|l} 
Netherlands \\
\end{tabular} & $2001-2006$ & 11 & 0 & $1 / 10$ & 34 & $11 / 0$ & $17 / 8$ & 0 & 19 \\
\hline Toso 2005 [29] & Netherlands & 1980-2003 & 25 & 0 & $2 / 23^{*}$ & 38 & $2 / 0$ & $2 / 0$ & 0 & 72 \\
\hline van der Windt $2006[30]$ & \begin{tabular}{|l} 
Netherlands \\
\end{tabular} & $2000-2005$ & 48 & 0 & $0 / 48^{*}$ & 36 & $3 / 0$ & $3 / 0$ & 0 & 24 \\
\hline Total (median, \%) & - & - & 1481 & 45 & $\begin{array}{l}\text { 152/1259 (M, } \\
11 \% ; \mathrm{F}, 89 \%)\end{array}$ & 36 & $148(93 / 55)$ & $189(104 / 85)$ & 9 & 40 \\
\hline
\end{tabular}

-, not available; $F$, female; $M$, male.

*Data of total cohort instead of embolized patients only if the specific information was not described in the original paper.

$\uparrow$ All patients from 27 European high-volume HPB units were underwent hepatic resection. 
by Erdogan [20, 21] were from the same department, respectively. All of them were included because the inclusion period was different [18-21]. Thus, the final list of included studies was formed by 21 studies (Table 1). In one study, TAE was performed with chemotherapy (TACE) [23]. Seven of these followed a prospective design $[10,12,18,21,25,28,30]$ and the overall quality of the studies was deemed sufficient (Attached Table).

\section{Characteristics of included patients}

These 21 studies included 1481 patients with HCAs, predominantly female $(89.2 \%)$. The median age was 36 years old. Of the 21 included studies [10-30], most of them (account for $99.5 \%$ population) were based on Western population [10-22, 24-30]. Of the total populations, most of them were underwent hepatic resection. Only 148 (10\%) patients (involving 189 lesions) received TAE, including $93(62.8 \%)$ patients with bleeding HCAs and $55(37.2 \%)$ patients with non-bleeding HCAs. Intended elective TAE was performed in 45/148 (30.4\%) patients, with a total of $73 / 189(38.6 \%)$ HCAs. Adenomatosis was observed in $9 / 148(6.1 \%)$ of the patients.

\section{Tumor reduction and symptoms improvement}

Eight of the twenty-one studies involving 78 (52.7\%) HCAs patients receiving TAE reported the change of the tumor size $[13,17-18,21-23,27-28]$. In the study by Bunchorntavakul and coworkers [13], only 14/17 patients with good follow-up obtained partial imaging response. Of the 14 patients, 11 (79\%) showed tumor size reduction, according to the revised RECIST [31]. Therefore, only 14 of the 17 patients were included into tumor reduction calculation. In other two studies [17, 22], tumor reduction calculation was based on number of tumors but not number of patients. Therefore, data of 107 tumors was suitable for application of the revised RECIST criteria (Table 2). The rates of Complete Response, Partial Response, Progressive Disease, and Stable Disease were 10.3\% (11/107), 73.8\% (79/107), 3.7\% (4/107), and 12.1\% (13/107), respectively. Tumor overall response rate (Complete Response + Partial Response) was $84.1 \%$.

Only one study involving seven patients received TACE reported symptoms improvement [23]. Presenting symptoms included abdominal pain $(n=4)$ and lowerextremity edema $(n=1)$. Two patients had no symptoms at presentation. Preexisting symptoms were relieved within 1 month after TACE (Table 2).

\section{Malignant transformation and surgery avoided}

Within a median follow-up time of 40 months, no malignant transformation was observed after TAE (Table
3). Hepatic resection was avoided in 72 of $148(48.6 \%)$ TAE treated patients. Of these, $23(31.9 \%)$ patients were with bleeding before TAE while 49 (68.1\%) with nonbleeding.

Of the 45 patients with intended elective TAE, 43 $(95.6 \%)$ patients did not require subsequent ( and not further) hepatic resection. However, hepatic resection was avoided in only $24.7 \%$ (23/93) patients with bleeding after acute TAE.

\section{Complications of TAE}

Most studies did not found complications related to TAE. No procedural complication or mortality was reported. However, some patients experienced self limited post-TAE syndrome, including pain, fever, nausea/ vomiting, and fatigue, but very few patients did this lead to a prolonged ( $>24 \mathrm{~h}$ ) hospital stay. Two patients with moderately post-TAE syndrome, leading to extended hospital stay or returning to emergency department [13]. Other two patients developed diabetic ketoacidosis ${ }^{13}$ or sepsis due to cyst after TAE [10].

\section{DISCUSSION}

Determining treatment options for HCAs is important. Many studies have developed criteria revolving around tumor size/number, oral contraceptives use, gender and more recently molecular classification, to help determine which patients require positive treatment [4, 19, 32-33]. Though hepatic resection is the primary mode of treatment to treat and/or prevent HCAs complications such as haemorrhage or malignant is suspected, some case reports and case series have reported the feasibility of TAE for the treatment of HCAs because of the utilization of TAE for HCC [10-30].However, the role of TAE to treat and prevent (re)bleeding, especially used in an elective setting, is unknown.

The present systematic review included 21 studies involving 1481 patients with HCAs. Of them, 148 patients (with 189 lesions) were treated with TAE for bleeding or non-bleeding HCAs. Tumor overall response rate was reach up to $84 \%$. Hepatic resection was avoided in near half of the TAE treated patients. In an elective setting, 95.6\% patients did not require further surgical management. Even in the setting of bleeding, hepatic resection was also avoided in $25 \%$ patients. Moreover, TAE was safe for HCAs.

The main risk of HCAs in the long-term is bleeding and malignant transformation. The risk of bleeding increases with increasing tumor diameter [4, 12]. Others suggest that bleeding in tumors $<5 \mathrm{~cm}$ is scarcely possible [16]. Therefore, HCAs $\geq 5 \mathrm{~cm}$ are recommended to be treated with hepatic resection [7, 16, 19]. However, many HCA patients are with multiple tumors. Resection and 
Table 2: Outcomes of the included studies

\begin{tabular}{|c|c|c|c|c|c|c|}
\hline Study & Reason of TAE & \begin{tabular}{|l|} 
Resection \\
avoided \\
(bleeding/ \\
non-bleeding) \\
\end{tabular} & $\begin{array}{l}\text { Reason (not) to perform } \\
\text { resection }\end{array}$ & $\begin{array}{l}\text { Malignant } \\
\text { transformation }\end{array}$ & $\begin{array}{ll}\text { Tumor } & \text { reduction } \\
\text { and } & \text { symptom } \\
\text { improvement }\end{array}$ & Complications \\
\hline Abu Hilal 2011 [10] & Bleeding $(n=3)$ & $0 / 0$ & $\begin{array}{l}\text { Need to rule out } \\
\text { malignancy }(n=2) ; \\
\text { preoperative diagnosis of } \\
\text { large HA }(n=1)\end{array}$ & - & - & $\begin{array}{l}\text { Sepsis due to } \\
\text { cyst after TAE } \\
(n=1)\end{array}$ \\
\hline Battula 2012 [11] & Bleeding $(n=2)$ & $2 / 0$ & $\begin{array}{l}\text { No resection needed: } \\
\text { tumor regression }(n=2)\end{array}$ & 0 & - & $\begin{array}{l}\text { No } \\
\text { complications }\end{array}$ \\
\hline Bieze 2014 [12] & $\begin{array}{l}\text { Bleeding }(n=7) \text {; TAE } \\
\text { to avoid intraoperative } \\
\text { bleeding }(n=2)\end{array}$ & $1 / 0$ & $\begin{array}{l}\text { No resection needed: } \\
\text { tumor regression }(n=1) \text {; } \\
\text { Resection according to } \\
\text { protocol }(n=8)\end{array}$ & 0 & - & $\begin{array}{l}\text { No } \\
\text { complications }\end{array}$ \\
\hline $\begin{array}{l}\text { Bunchorntavakul } \\
2011[13]\end{array}$ & $\begin{array}{l}\text { TAE prior to resection } \\
(n=6) ; \text { TAE after } \\
\text { resection }(n=2) ; \\
\text { pregnancy }(n=1) ; \\
\text { study purpose }(n=6) ; \\
\text { not clear }(n=2)\end{array}$ & $2 / 7$ & $\begin{array}{l}\text { No resection needed: } \\
\text { tumor regression }(n=9) \\
\text { resection according to } \\
\text { protocol }(n=8)\end{array}$ & 0 & $\begin{array}{l}\text { Good response and } \\
\text { reduction of the tumor } \\
\text { lesions in } 79 \% \text {; } \\
\text { CR }(n=0), \operatorname{PR}(n=11) \text {, } \\
\operatorname{PD}(n=1) ; \operatorname{SD}(n=2)^{*}\end{array}$ & $\begin{array}{l}\text { Two with } \\
\text { moderately } \\
\text { severe } \\
\text { postembolisation } \\
\text { syndrome, } \\
\text { leading to } \\
\text { extended } \\
\text { hospital stay } \\
\text { or returning } \\
\text { to emergency } \\
\text { department. } \\
\text { One developed } \\
\text { diabetic } \\
\text { ketoacidosis. } \\
\end{array}$ \\
\hline Cho 2008 [14] & Bleeding $(n=1)$ & $0 / 0$ & $\begin{array}{l}\text { Resection according to } \\
\text { protocol }(n=1)\end{array}$ & 0 & - & $\begin{array}{l}\text { No } \\
\text { complications }\end{array}$ \\
\hline de'Angelis 2014 [15] & Bleeding $(n=6)$ & $0 / 0$ & $\begin{array}{l}\text { Resection according to } \\
\text { protocol }(n=6)\end{array}$ & 0 & - & $\begin{array}{l}\text { No } \\
\text { complications }\end{array}$ \\
\hline Deneve 2009 [16] & $\begin{array}{l}\text { Bleeding }(n=6) ; \\
\text { reason not described } \\
(n=5)\end{array}$ & $0 / 5$ & $\begin{array}{l}\text { No resection needed: } \\
\text { reason not clear }(n=5) ; \\
\text { resection according to } \\
\text { protocol }(n=6)\end{array}$ & 0 & - & $\begin{array}{l}\text { No } \\
\text { complications }\end{array}$ \\
\hline Deodhar 2011 [17] & $\begin{array}{l}\text { Bleeding }(n=1) \text {; } \\
\text { abdominal pain } \\
(n=1) ; \text { presumed } \\
\begin{array}{l}\text { increased risk of } \\
\text { bleeding }(n=6)\end{array}\end{array}$ & $1 / 5$ & $\begin{array}{l}\text { No resection needed: } \\
\text { tumor regression }(n=6) \text {; } \\
\text { resected for continued } \\
\text { peripheral enhancement } \\
(n=2)\end{array}$ & 0 & $\begin{array}{l}\mathrm{CR}(n=2), \operatorname{PR}(n=10) \\
\mathrm{PD}(n=2) ; \operatorname{SD}(n=3)^{\dagger}\end{array}$ & $\begin{array}{l}\text { No procedural } \\
\text { complications. } \\
\text { Most patients } \\
\text { had elements } \\
\text { of self limited } \\
\text { postembolization } \\
\text { syndrome, } \\
\text { including pain, } \\
\text { fever, nausea/ } \\
\text { vomiting, and } \\
\text { fatigue, but in } \\
\text { no patient did } \\
\text { this lead to a } \\
\text { prolonged ( }>24 \\
\text { h) hospital stay. }\end{array}$ \\
\hline Dokmak 2009 [19] & Bleeding $(n=12)$ & $0 / 0$ & $\begin{array}{l}\text { Resection according to } \\
\text { protocol }(n=12)\end{array}$ & 0 & - & $\begin{array}{l}\text { No } \\
\text { complications }\end{array}$ \\
\hline Dokmak 2015 [18] & Bleeding $(n=2)$ & $0 / 2$ & $\begin{array}{l}\text { No resection needed: } \\
\text { tumor regression }(n=2)\end{array}$ & 0 & $\begin{array}{l}\mathrm{CR}(n=1), \operatorname{PR}(n=1) \\
\mathrm{PD}(n=0) ; \operatorname{SD}(n=0)\end{array}$ & $\begin{array}{l}\text { No } \\
\text { complications }\end{array}$ \\
\hline Erdogan 2006 [20] & Bleeding $(n=2)$ & $1 / 0$ & $\begin{array}{l}\text { No resection needed: } \\
\text { tumor regression }(n=1) ; \\
\text { resection according to } \\
\text { protocol }(n=1)\end{array}$ & 0 & - & $\begin{array}{l}\text { No } \\
\text { complications }\end{array}$ \\
\hline Erdogan 2007 [21] & $\begin{array}{l}\text { Bleeding }(\mathrm{n}=4) \text {; to } \\
\text { reduce the tumor mass } \\
>5 \mathrm{~cm}(n=2)\end{array}$ & $0 / 4$ & $\begin{array}{l}\text { No resection needed: } \\
\text { tumor regression }(n=4) \text {; } \\
\text { laparotomy for removal } \\
\text { of the large, intra- } \\
\text { abdominal hematoma }(n \\
=2)\end{array}$ & 0 & $\begin{array}{l}\mathrm{CR}(n=1), \operatorname{PR}(n=4), \\
\operatorname{PD}(n=0) ; \operatorname{SD}(n=1)\end{array}$ & $\begin{array}{l}\text { No } \\
\text { complications }\end{array}$ \\
\hline
\end{tabular}




\begin{tabular}{|c|c|c|c|c|c|c|}
\hline Karkar 2013 [22] & $\begin{array}{l}\text { Suspicion } \\
\text { malignancy }(n=14) \\
\text { haemorrhage }(n=5) \\
\text { large tumor }(n=1) \\
\text { local recurrence after } \\
\text { resection }(n=1)^{\dagger}\end{array}$ & $5 / 19$ & $\begin{array}{l}\text { No resection needed: } \\
\text { tumor regression }(n=24)\end{array}$ & 0 & $\begin{array}{l}\mathrm{CR}(n=5), \mathrm{PR}(n=22), \\
\mathrm{PD}(n=0), \mathrm{SD}(n=7)^{\dagger}\end{array}$ & $\begin{array}{l}\text { No } \\
\text { complications }\end{array}$ \\
\hline Kim 2007 [23] & $\begin{array}{l}\text { Impending rupture }(n \\
=6) ; \text { bleeding }(n=1)\end{array}$ & $1 / 6$ & $\begin{array}{l}\text { No resection needed: } \\
\text { regression tumor }(n=7)\end{array}$ & 0 & $\begin{array}{l}\text { Preexisting symptoms } \\
\text { were relieved within 1 } \\
\text { month after TACE. CR } \\
(n=2), \text { PR }(n=4), \text { PD } \\
(n=1) ; \mathrm{SD}(n=0)\end{array}$ & \begin{tabular}{l}
\multicolumn{2}{l}{ Immediately } \\
after TACE, \\
most patients \\
experienced \\
nausea fever, \\
or abdominal \\
pain; however, \\
all symptoms \\
disappeared \\
within 5 days.
\end{tabular} \\
\hline Laurent 2016 [24] & Bleeding $(n=15)$ & $0 / 0$ & $\begin{array}{l}\text { Resection according to } \\
\text { protocol }(\mathrm{n}=15)\end{array}$ & 0 & - & - \\
\hline Marini 2002 [25] & Bleeding $(n=3)$ & $0 / 0$ & $\begin{array}{l}\text { Resection according to } \\
\text { protocol }(n=3)\end{array}$ & 0 & - & $\begin{array}{l}\text { No } \\
\text { complications }\end{array}$ \\
\hline Ramia 2014 [26] & Bleeding $(n=1)$ & $0 / 0$ & $\begin{array}{l}\text { Resection according to } \\
\text { protocol }(n=1)\end{array}$ & 0 & - & $\begin{array}{l}\text { No } \\
\text { complications }\end{array}$ \\
\hline $\begin{array}{l}\text { Srirattanapong } 2014 \\
\text { [27] }\end{array}$ & $\begin{array}{l}\text { High risk for resection } \\
(n=1) ; \text { remaining } \\
\text { adenoma after surgery } \\
(n=1)\end{array}$ & $1 / 1$ & $\begin{array}{l}\text { No resection needed: } \\
\text { tumor regression }(n=2)\end{array}$ & 0 & $\begin{array}{l}\mathrm{CR}(n=0), \mathrm{PR}(n=2), \\
\mathrm{PD}(n=0) ; \mathrm{SD}(n=0)\end{array}$ & $\begin{array}{l}\text { No } \\
\text { complications }\end{array}$ \\
\hline Stoot 2007 [28] & Bleeding $(n=11)$ & $9 / 0$ & $\begin{array}{l}\text { No resection needed: } \\
\text { tumor regression }(n= \\
9) ; \text { elective resection } \\
\text { according to protocol }(n \\
=2)\end{array}$ & 0 & $\begin{array}{l}\text { The median decrease in } \\
\text { tumor size was } 5.0 \mathrm{~cm} \\
\text { after TAE. CR }(n=0) \text {, } \\
\text { PR }(n=25), \operatorname{PD}(n=0) \\
\text { SD }(n=0)\end{array}$ & $\begin{array}{l}\text { No } \\
\text { complications }\end{array}$ \\
\hline Toso 2005 [29] & Bleeding $(n=2)$ & $0 / 0$ & $\begin{array}{l}\text { Resection according to } \\
\text { protocol }(n=2)\end{array}$ & 0 & - & $\begin{array}{l}\text { No } \\
\text { complications }\end{array}$ \\
\hline $\begin{array}{l}\text { van der Windt } 2006 \\
{[30]}\end{array}$ & Bleeding $(n=3)$ & $0 / 0$ & $\begin{array}{l}\text { Emergency resection }(n= \\
1) ; \text { due to pregnant }(n= \\
1) \text { or for persistent tumor } \\
(n=1)\end{array}$ & 0 & - & $\begin{array}{l}\text { No } \\
\text { complications }\end{array}$ \\
\hline Total (\%) & $\begin{array}{l}\text { Bleeding }(n=93), \\
\text { other reasons }(n= \\
55)\end{array}$ & $\begin{array}{l}\text { Surgery } \\
\text { avoided, } n= \\
72(23 / 49)\end{array}$ & $\begin{array}{l}\text { Performed resection, } n \\
=76\end{array}$ & 0 & $\begin{array}{l}\text { CR }(n=11), \text { PR }(n= \\
79), \text { PD }(n=4) ; \text { SD }(n \\
=13)\end{array}$ & - \\
\hline
\end{tabular}

-, not available; TAE, transarterial embolization; TACE, transarterial chemoembolization.

* Only 14/17 patients with good follow-up.

$\dagger$ Number of tumors but not number of patients.

$\mathrm{CR}$, complete response; PD, progressive disease; PR, partial response; SD, stable disease.

radiofrequency ablation (RFA) may be not practical for such patients because each is limited by tumor size and number, location, and volume of liver. Moreover, resection carries an increased risk of postoperative morbidity and a long recovery time, which limited resection as the optimal therapy. TAE may be an optional treatment. Karkar and coworkers [22] retrospectively compared the outcomes of resection, TAE, and observation for 52 patients with 100 adenomas. They found solitary HCA are frequently resected, multifocal HCAs are often TAE, and small HCAs can safely be observed. Due to the heterogeneity among included studies and missing data in more than half of the included studies, we did not extract data of tumor size and number. So the present systematic review can't find out the association between indication of TAE and tumor size/ number.

Both TAE and RFA are percutaneous minimally invasive techniques that spare liver parenchyma and avoid laparotomy. They are preferred over hepatic resection in selected HCC [34]. In selected HCAs, these two techniques are also safe and effective. Cost-effective analysis found RFA is the most favorable treatment strategy for patients with small HCAs. However, in cases unsuitable for RFA, watchful waiting combined 
with TAE had the highest effectiveness and lowest costs [35]. Because HCAs most frequently occurs in young females, RFA and TAE with favorable cosmetic results are attractive. More importantly, TAE can be applied to most patients. In the present review, elective TAE can lead to 95\% HCAs patients avoided further resection. One quarter HCAs patients with haemorrhage also avoided further resection after TAE. In addition, higher tumor response rate will significantly relief symptoms. Therefore, the efficacy of TAE for select HCAs is definite.

In general, TAE is safe since significant complications were rare. The most common complication among patients included in this systematic review was self limited post-TAE syndrome, including pain, fever, nausea/vomiting, and fatigue. Diabetic ketoacidosis or sepsis due to cyst after TAE was developed in one $(0.7 \%)$ patient, respectively. No mortality was found in this review. However, in-hospital mortality associated with TAE was $1.0 \%$ in big national survey [36]. Whether this discrepancy is caused by an actual physiological difference between HCAs and HCC is unclear. Another reason may be the usage of chemotherapeutic agents. One included study used TACE for HCAs [23]. Because HCAs are benign tumors, addition of chemotherapeutic agents to TAE may have no beneficial effects, but may results in chemotherapy-related side effects.

More than half of the included patients were evaluated tumor reduction with revised RECIST criteria [31]. This method allows us objective and quantitative assessment of the data [37]. However, using the revised RECIST criteria only base on tumor size also has limitations. On one hand, persistent contrast enhancement during imaging may be concomitant with tumor size reduction. On the other hand, the range of Partial Response and Progressive Disease are too wide, leading to inevitable loss of detail.

The short median follow-up of 40 months precluded any statement regarding the ability of TAE to mitigate the risk of malignant transformation. As a benign tumor, HCA grows slowly. Lack of high level evidence studies in literature is another limitation. Retrospectively designed studies have potential bias that the positive effects of TAE are overestimated, as cases with unsuccessful TAE are less likely to be reported. However, hepatic resection is always the first-line therapy for HCAs, may lead to an underestimation of actual beneficial effect of TAE. The second underestimation the efficacy of TAE is hepatic resection performed after TAE for size reduction. Some patients with Partial Response or Stable Disease after TAE may not need further surgical management, but they still received hepatic resection. And last, HCAs patients received TAE alone, TAE before resection, or TAE after resection were included into analysis, therefore, potentially has lead to overestimation or underestimation of the number of avoided resections after TAE.

In conclusion, either in an elective setting or in the setting of bleeding, TAE can be considered safe in the management of HCAs. The ability of elective TAE to reduce tumor size and symptoms of tumors, especially avoid surgical management, make it as a reasonable alternative management to hepatic resection. However, since the limitations of the present review and the risk of malignant transformation after TAE is still uncertain, large prospective studies with long-term follow-up would be helpful in confirming the role of TAE in the management of HCAs.

\section{MATERIALS AND METHODS}

\section{Literature search strategy}

A systematic search of EMBASE, Scopus and PubMed databases was performed for articles published between 1 January 2000 and 20 December 2016 relevant to TAE for HCAs. The systematic review was carried out in accordance with the PRISMA statement for reporting systematic reviews of studies that evaluate healthcare interventions [38]. The medical subject headings (MeSH) "hepatocellular adenoma" and "embolization" were used and the following keywords were added to refine the literature research: "hepatic adenoma" and "transarterial embolization". Results from the two electronic databases were compared to obtain a list of unique articles for screening. Relevant references of all included studies were also searched manually to identify additional studies. Gray literature was not included in the present analysis.

\section{Literature screening}

Two authors (B.-H.Y and Y.-H.L) independently conducted an initial screen to identify articles clearly relevant by title, abstract and keywords of publication. Then, study selection was accomplished through three levels of screening. At level 1, studies were excluded because they were reviews, letters, editorials, or comments, or were in languages other than English. Then, these two independent reviewers (B.-H.Y and Y.-H.L) assessed the studies for relevance, inclusion or not. At level 2, abstracts of retained studies were reviewed for relevance. Abstracts entered the subsequent screening level if they reported clinical outcome of series of patients with HCAs treated with TAE. For level 3 screening, the full text was obtained for relevant studies and for any references for which a decision could not be made on the basis of the abstract. And methodological quality was assessed in level 3.

\section{Selection criteria}

Criteria for final study inclusion of the present systematic review were: (a) studies published after 
2000 when radiological interventional techniques were commonly utilized; (b) study population included patients with HCAs treated by elective or emergent TAE (TAE alone, prior to surgery, or after surgery); (c) comparative studies, cohort studies, case series or case reports with at least four patients that reported on the outcomes of TAE in patients with HCAs. In cases in which a study was followed by a more complete study or studies that included the original data set, the complete report was chosen. Such linked studies were identified on the grounds of authorship, institutions, and included period. In order to reduce selection bias, case reports with less than three patients were excluded. Studies reporting rather than outcomes of TAE (for example, cost-effectiveness) were also excluded.

\section{Data collection and definitions}

Data were extracted by two authors (B.-H.Y and Y.-H.L) using standardized forms. The following data were collected: family name of the first author and publication year, country and included period of included populations, study design, demographics of patients with TAE, and outcomes of TAE. Data collected with respect to the primary objective were: reported reduction in tumor size, indication for TAE (elective or emergency setting), number and reason of avoided resections, reason (not) to perform hepatic resection, malignant transformation, and complications of TAE. Any discrepancies in inclusion were resolved by discussion between the reviewers and a third investigator (Y.-P.Y). The quality of each selected study was assessed by means of the quality appraisal tool for case series studies using a modified Delphi technique [39].

TAE can be used as electivity and emergency. Emergent TAE was always used to treat active bleeding or avoid intraoperative bleeding. Elective TAE was defined as an alternative treatment to resection and used for nonbleeding HCAs or not for prevention of intraoperative blood loss. Avoided hepatic resection was defined as no further resection was necessary after TAE due to reduction of tumor size or involution of tumor, and/or relief of complaints within the follow-up period. However, those with tumor stable in size or unresectable tumor before and after TAE were not regarded as avoided hepatic resection.

Tumor response rate of target lesions defined according to the revised Response Evaluation Criteria in Solid Tumors (RECIST) represented another primary outcome measures [31]. lesions.

Complete Response: Disappearance of all target

Partial Response: At least a 30\% decrease in the sum of diameters of target lesions, taking as reference the baseline sum diameters.

Progressive Disease: At least a 20\% increase in the sum of diameters of target lesions.
Stable Disease: Neither sufficient shrinkage to qualify for Partial Response nor sufficient increase to qualify for Progressive Disease, taking as reference the smallest sum diameters while on study.

\section{Statistical analysis}

Meta-analysis was not performed because of substantial heterogeneity among studies. Data were tabulated and presented as numbers (with percentages) and mean or median values. When studies reported continuous variables as median and range, the mean and variance were estimated taking into account the size of the sample as proposed by Wan and coworkers [40].

\section{Authors' contributions}

Guarantors of integrity of entire study, L.M.; study concepts/study design or data acquisition or data analysis/interpretation, all authors; manuscript drafting or manuscript revision for important intellectual content, all authors; manuscript final version approval, all authors; literature research, B.H.Y., R.H.L.; statistical analysis, B.H.Y., B.K.A.; and manuscript editing, L.M., T.Y., W.P.Y.

\section{CONFLICTS OF INTEREST}

There is no conflict of interest.

\section{FUNDING}

This work was supported in part by the National Natural Science Foundation of China (No. 81472284 and 81672699) and Program for Excellent Young Scholars of SMMU and State Key Project on Infectious Diseases of China (No. 2012ZX10002-016).

\section{REFERENCES}

1. Vijay A, Elaffandi A, Khalaf H. Hepatocellular adenoma: An update. World J Hepatol. 2015;7:2603-2609.

2. Rooks JB, Ory HW, Ishak KG, Strauss LT, Greenspan JR, Hill AP, Tyler CW Jr. Epidemiology of hepatocellular adenoma. The role of oral contraceptive use. JAMA. 1979;242:644-648.

3. Bioulac-Sage P, Balabaud C, Zucman-Rossi J. Focal nodular hyperplasia, hepatocellular adenomas: past, present, future. Gastroenterol Clin Biol. 2010;34:355-358.

4. Nault JC, Couchy G, Balabaud C, Morcrette G, Caruso $\mathrm{S}$, Blanc JF, Bacq Y, Calderaro J, Paradis V, Ramos J, Scoazec JY, Gnemmi V, Sturm N, et al. Molecular Classification of Hepatocellular Adenoma Associates With Risk Factors, Bleeding, and Malignant Transformation. Gastroenterology. 2017; 152:880-894.e6. doi: 10.1053/j. 
gastro.2016.1011.1042.

5. Farges O, Ferreira N, Dokmak S, Belghiti J, Bedossa P, Paradis V. Changing trends in malignant transformation of hepatocellular adenoma. Gut. 2011;60:85-89.

6. An SL, Wang LM, Rong WQ, Wu F, Sun W, Yu WB, Feng L, Liu FQ, Tian F, Wu JX. Hepatocellular adenoma with malignant transformation in male patients with noncirrhotic livers. Chin J Cancer. 2015;34:217-224.

7. Stoot JH, Coelen RJ, De Jong $\mathrm{MC}$, Dejong $\mathrm{CH}$. Malignant transformation of hepatocellular adenomas into hepatocellular carcinomas: a systematic review including more than 1600 adenoma cases. HPB (Oxford). 2010;12:509-522.

8. Agrawal S, Agarwal S, Arnason T, Saini S, Belghiti J. Management of Hepatocellular Adenoma: Recent Advances. Clin Gastroenterol Hepatol. 2015;13:1221-1230.

9. Bioulac-Sage P, Laumonier H, Couchy G, Le Bail B, Sa Cunha A, Rullier A, Laurent C, Blanc JF, Cubel G, Trillaud H, Zucman-Rossi J, Balabaud C, Saric J. Hepatocellular adenoma management and phenotypic classification: the Bordeaux experience. Hepatology. 2009;50:481-489.

10. Abu Hilal M, Di Fabio F, Wiltshire RD, Hamdan M, Layfield DM, Pearce NW. Laparoscopic liver resection for hepatocellular adenoma. World J Gastrointest Surg. 2011;3:101-105.

11. Battula N, Tsapralis D, Takhar A, Coldham C, Mayer D, Isaac J, Muiesan P, Sutcliffe RP, Marudanayagam R, Mirza $\mathrm{DF}$, Bramhall SR. Aetio-pathogenesis and the management of spontaneous liver bleeding in the West: a 16-year singlecentre experience. HPB (Oxford). 2012;14:382-389.

12. Bieze M, Phoa SS, Verheij J, van Lienden KP, van Gulik TM. Risk factors for bleeding in hepatocellular adenoma. Br J Surg. 2014;101:847-855.

13. Bunchorntavakul C, Bahirwani R, Drazek D, Soulen MC, Siegelman ES, Furth EE, Olthoff K, Shaked A, Reddy KR. Clinical features and natural history of hepatocellular adenomas: the impact of obesity. Aliment Pharmacol Ther. 2011;34:664-674.

14. Cho SW, Marsh JW, Steel J, Holloway SE, Heckman JT, Ochoa ER, Geller DA, Gamblin TC. Surgical management of hepatocellular adenoma: take it or leave it? Ann Surg Oncol. 2008;15:2795-2803.

15. de'Angelis N, Memeo R, Calderaro J, Felli E, Salloum C, Compagnon P, Luciani A, Laurent A, Cherqui D, Azoulay D. Open and laparoscopic resection of hepatocellular adenoma: trends over 23 years at a specialist hepatobiliary unit. HPB (Oxford). 2014;16:783-788.

16. Deneve JL, Pawlik TM, Cunningham S, Clary B, Reddy S, Scoggins CR, Martin RC, D'Angelica M, Staley CA, Choti MA, Jarnagin WR, Schulick RD, Kooby DA. Liver cell adenoma: a multicenter analysis of risk factors for rupture and malignancy. Ann Surg Oncol. 2009;16:640-648.

17. Deodhar A, Brody LA, Covey AM, Brown KT, Getrajdman GI. Bland embolization in the treatment of hepatic adenomas: preliminary experience. J Vasc Interv Radiol. 2011;22:795-799; quiz 800.

18. Dokmak S, Belghiti J. Will weight loss become a future treatment of hepatocellular adenoma in obese patients? Liver Int. 2015;35:2228-2232.

19. Dokmak S, Paradis V, Vilgrain V, Sauvanet A, Farges O, Valla D, Bedossa P, Belghiti J. A single-center surgical experience of 122 patients with single and multiple hepatocellular adenomas. Gastroenterology. 2009;137:1698-1705.

20. Erdogan D, Busch OR, van Delden OM, Ten Kate FJ, Gouma DJ, van Gulik TM. Management of spontaneous haemorrhage and rupture of hepatocellular adenomas. A single centre experience. Liver Int. 2006;26(4):433-438.

21. Erdogan D, van Delden OM, Busch OR, Gouma DJ, van Gulik TM. Selective transcatheter arterial embolization for treatment of bleeding complications or reduction of tumor mass of hepatocellular adenomas. Cardiovasc Intervent Radiol. 2007;30:1252-1258.

22. Karkar AM, Tang LH, Kashikar ND, Gonen M, Solomon SB, Dematteo RP, D' Angelica MI, Correa-Gallego C, Jarnagin WR, Fong Y, Getrajdman GI, Allen P, Kingham TP. Management of hepatocellular adenoma: comparison of resection, embolization and observation. HPB (Oxford). 2013;15:235-243.

23. Kim YI, Chung JW, Park JH. Feasibility of transcatheter arterial chemoembolization for hepatic adenoma. J Vasc Interv Radiol. 2007;18:862-867.

24. Laurent A, Dokmak S, Nault JC, Pruvot FR, Fabre JM, Letoublon C, Bachellier P, Capussotti L, Farges O, Mabrut JY, Le Treut YP, Ayav A, Suc B. et al. European experience of 573 liver resections for hepatocellular adenoma: a crosssectional study by the AFC-HCA-2013 study group. HPB (Oxford). 2016;18:748-755.

25. Marini P, Vilgrain V, Belghiti J. Management of spontaneous rupture of liver tumours. Dig Surg. 2002;19:109-113.

26. Ramia JM, Bernardo C, Valdivieso A, Dopazo C, Jover JM, Albiol MT, Pardo F, Fernandez Aguilar JL, Gutierrez Calvo A, Serrablo A, Diez Valladares L, Pereira F, Sabater $\mathrm{L}$, et al. Multicentre study on hepatic adenomas. [Article in Spanish] Cir Esp. 2014;92:120-125.

27. Srirattanapong S, Angthong W, Kim BS, Hayashi PH, Gerber DA, Woosley JT, Peacock J, Ranatunga A, Semelka RC. Liver adenomatosis: serial investigation on MRI. Abdom Imaging. 2014;39:269-282.

28. Stoot JH, van der Linden E, Terpstra OT, Schaapherder AF. Life-saving therapy for haemorrhaging liver adenomas using selective arterial embolization. Br J Surg. 2007;94:1249-1253.

29. Toso C, Majno P, Andres A, Rubbia-Brandt L, Berney T, Buhler L, Morel P, Mentha G. Management of hepatocellular adenoma: solitary-uncomplicated, multiple and ruptured tumors. World J Gastroenterol. 2005;11:5691- 
5695.

30. van der Windt DJ, Kok NF, Hussain SM, Zondervan PE, Alwayn IP, de Man RA, IJzermans JN. Case-orientated approach to the management of hepatocellular adenoma. Br J Surg. 2006;93:1495-1502.

31. Eisenhauer EA, Therasse P, Bogaerts J, Schwartz LH, Sargent D, Ford R, Dancey J, Arbuck S, Gwyther S, Mooney M, Rubinstein L, Shankar L, Dodd L, Kaplan R, Lacombe D, Verweij J. New response evaluation criteria in solid tumours: revised RECIST guideline (version 1.1). Eur J Cancer. 2009;45:228-247.

32. Klompenhouwer AJ, Sprengers D, Willemssen FE, Gaspersz MP, Ijzermans JN, De Man RA. Evidence of good prognosis of hepatocellular adenoma in post-menopausal women. J Hepatol. 2016;65:1163-1170.

33. McInnes MD, Hibbert RM, Inacio JR, Schieda N. Focal Nodular Hyperplasia and Hepatocellular Adenoma: Accuracy of Gadoxetic Acid-enhanced MR Imaging-A Systematic Review. Radiology. 2015;277:413-423.

34. Guo Z, Zhong JH, Jiang JH, Zhang J, Xiang BD, Li LQ. Comparison of survival of patients with BCLC stage A hepatocellular carcinoma after hepatic resection or transarterial chemoembolization: a propensity score-based analysis. Ann Surg Oncol. 2014;21:3069-3076.

35. van der Sluis FJ, Bosch JL, Terkivatan T, de Man RA, Ijzermans JN, Hunink MG. Hepatocellular adenoma: costeffectiveness of different treatment strategies. Radiology. 2009;252:737-746.
36. Sato M, Tateishi R, Yasunaga H, Horiguchi H, Yoshida H, Matsuda S, Koike K. Mortality and morbidity of hepatectomy, radiofrequency ablation, and embolization for hepatocellular carcinoma: a national survey of 54,145 patients. J Gastroenterol. 2012;47:1125-1133.

37. Edeline J, Boucher E, Rolland Y, Vauléon E, Pracht M, Perrin C, Le Roux C, Raoul JL. Comparison of tumor response by Response Evaluation Criteria in Solid Tumors (RECIST) and modified RECIST in patients treated with sorafenib for hepatocellular carcinoma. Cancer. 2012;118:147-156.

38. Liberati A, Altman DG, Tetzlaff J, Mulrow C, Gøtzsche PC, Ioannidis JP, Clarke M, Devereaux PJ, Kleijnen J, Moher D. The PRISMA statement for reporting systematic reviews and meta-analyses of studies that evaluate healthcare interventions: explanation and elaboration. BMJ. 2009;339:b2700.

39. Moga C, Guo B, Schopflocher D, Harstall C. Development of a Quality Appraisal Tool for Case Series Studies Using a Modified Delphi Technique. Edmonton AB: Institute of Health Economics. 2012.

40. Wan X, Wang W, Liu J, Tong T. Estimating the sample mean and standard deviation from the sample size, median, range and/or interquartile range. BMC Med Res Methodol. 2014; $14: 135$. 